\title{
Robot-Assisted Radical Prostatectomy: A Survey on the Influence of Postoperative Results Analysis and Surgical Video Review on Postoperative Complications and Functional Results.
}

Alexander J.W. Beulens ( $\sim$ alexander.beulens@catharinaziekenhuis.nl )

Nederlands Instituut voor Onderzoek van de Gezondheidszorg https://orcid.org/0000-0002-7105-1011

Hans Veerman

Antoni van Leeuwenhoek Nederlands Kanker Instituut

Willem Brinkman

Universitair Medisch Centrum Utrecht

Evert Koldewijn

Catharina Ziekenhuis

Ad Hendrikx

Catharina Ziekenhuis

Jean Paul van Basten

Canisius Wilhelmina Ziekenhuis

Jeroen van Merrienboer

Universiteit Maastricht

Chris Bangma

Erasmus MC

Cordula Wagner

Nederlands Instituut voor Onderzoek van de Gezondheidszorg

Henk van der Poel

Antoni van Leeuwenhoek Nederlands Kanker Instituut

Research

Keywords: Robotics, Prostate Cancer, Incontinence, robot assisted surgery, video review, results analysis, RARP, Quality of care

Posted Date: June 23rd, 2020

DOI: https://doi.org/10.21203/rs.3.rs-37053/v1 
License: (c) (i) This work is licensed under a Creative Commons Attribution 4.0 International License. Read Full License 


\section{Abstract}

\section{Background:}

Effective training and assessment of performance are fundamental to ensuring that surgeons reach their intended goal and operate safely with maximum preservation of functions. The field of video review and postoperative results analysis is focused on predicting postoperative results and reducing complications. Even though multiple groups have investigated the possibility of video review it is unclear if video review has found its place in daily clinical practice. To investigate the experiences and opinions of surgeons in the field of Robot-assisted Radical Prostatectomy (RARP) on the influence of video reviews and postoperative results analysis on postoperative complications and functional results.

Design, Setting, and Participants: RARP surgeons who were expected to perform video reviews and postoperative results analysis were identified. A total of 93 RARP surgeons were invited to participate in this survey. Online questionnaires were distributed. The questionnaire contained the following domains: background information of the RARP surgeons, evaluation of the use of postoperative results analysis and surgical video review, and future recommendations.

Results: A total of 30 RARP surgeons responded to the questionnaire. 27 respondents organized periodical results analyses, 17 of them reviewed edited videos as part of standard clinical practice in their hospital. Most respondents recommend video review, and are convinced it improves outcomes through self-reflection, feedback from a colleague, or from seeing different techniques and 'tricks'.

Conclusion: RARP surgeons have accepted the implementation of postoperative results analysis and surgical video review as forms of quality assurance and self-reflection. They use edited surgical videos to gain insight into the specific facets of RARP related to postoperative complications and functional outcomes.

\section{Introduction}

In the USA, approximately $90 \%$ of the radical prostatectomy surgeries are performed using the surgical robot,. ${ }^{1}$ i.e. Robot-Assisted Radical Prostatectomy (RARP). The influence of the surgical skills during RARP on surgical complications and functional outcomes has been investigated, but the specific surgical steps influencing urinary continence and erectile function remain unclear so far. ${ }^{1-3}$

In general, laparoscopic and robotic surgery provides the possibility to evaluate surgeons' skills based on intracorporal surgical videos. ${ }^{4,5}$ Analysis of these videos offers the opportunity to gain insight into past performance and to relate intraoperative events to adverse postoperative outcomes to learn for the future ${ }^{6-9}$.

Effective training and assessment of performance are fundamental to ensuring that surgeons reach their intended goal and operate safely with maximum preservation of functions. ${ }^{7,10,11}$ The field of video review 
and postoperative results analysis is focused on predicting postoperative results and reducing complications. ${ }^{1,2,12,13}$ Even though multiple groups have investigated the possibility of video review it is unclear if video review has found its place in daily clinical practice. Earlier research of our group has shown Dutch experts are willing to participate in surgical video review. ${ }^{1}$ Results have shown $92 \%$ of the respondents assume the use of surgical video review leads to recognition of errors and identification of possible improvements which can result in an improvement in surgical technique which can, in turn, contribute to the reduction of postoperative complications. ${ }^{1}$

To gain insight into the use, extent and possible effect of postoperative results analysis and surgical video review in daily clinical practice, a survey was performed amongst international RARP surgeons. The following key questions had to be answered:

Is postoperative results analysis and surgical video review implemented in daily practice RARP surgeons?

What different strategies of postoperative results analysis and surgical video review are used by the RARP surgeons?

Do these surgeons assume postoperative results analysis and surgical video review to be useful in improving daily practice and reduce complications?

Can RARP surgeons indicate which factors have their interest during postoperative results analysis and surgical video review related to improvement of postoperative functional outcomes and reduction complications?

\section{Method}

To obtain information on the experienced influence of video reviews and postoperative results analysis on complications and postoperative functional outcome, a questionnaire (supplementary data 1) was sent to investigate the opinions of RARP surgeons.

\section{Surgeon panel}

The surgeons were identified based on a multitude of factors: expected to perform video reviews and postoperative results analysis, have a known scientific interest in RARP through publications, have a high caseload, recommendation by an expert (HvdP), being a proctor or educator of a robotic fellowship, or being a staff member in one of the CC-ERUS-EAU host centers. Based on these (soft) criteria 93 RARP surgeons were invited to participate in this survey. Informed consent was obtained from all participants included in the study.

\section{Questionnaire}

The questionnaire (supplementary data 1) contained questions on: background information about the respondents, evaluation of the use of postoperative results analysis, evaluation of the use of surgical 
video review, the influence of postoperative results analysis and surgical video review on daily practice, and future recommendations on postoperative results analysis and surgical video review. The questionnaire was sent using the self-service function of the Data Management module developed by Research Manager https://my-researchmanager.com/en/home-2/.

\section{Statistical analysis}

In this descriptive study, data was presented as frequency distribution with percentages. Data was analyzed with SPSS v25 (IBM Corp., Armonk, NY, USA).

\section{Results}

A total of 30 RARP surgeons (32\%) responded to the survey, two responses were incomplete. A total of 24 $(80 \%)$ had at least five (or more) years of experience (Table 1). A total of $22(73 \%)$ participants performed more than 500 RARPs in their career. The hospitals of 14 (47\%) respondents were part of a combination of medical centers that work together in the field of prostate cancer care. The surgeons originated from all over the world (Table 1). Of the respondents 19 (63\%) worked in a ERUS Robotic Certified Host centre. 
Table 1: Respondent characteristics

\begin{tabular}{|c|c|}
\hline Total respondents (\%/invitees) & $30(32 \%)$ \\
\hline \multicolumn{2}{|l|}{ Occupation* } \\
\hline Fellow & $1(3.3 \%)$ \\
\hline Urologist & $29(97 \%)$ \\
\hline Professor & $12(40 \%)$ \\
\hline Chief & $9(30 \%)$ \\
\hline Trainer & $9(30 \%)$ \\
\hline \multicolumn{2}{|l|}{ Years of experience } \\
\hline 0 to 5 & $6(20 \%)$ \\
\hline 6 to 10 & $4(13 \%)$ \\
\hline 11 to 15 & $10(33 \%)$ \\
\hline 16 to 20 & $8(27 \%)$ \\
\hline More than 20 & $2(6.7 \%)$ \\
\hline \multicolumn{2}{|l|}{ RARPs performed personally } \\
\hline$\leq 500$ & $8(27 \%)$ \\
\hline 501 to 1000 & $4(13 \%)$ \\
\hline 1001 to 1500 & $3(10 \%)$ \\
\hline 1501 to 2000 & $5(17 \%)$ \\
\hline 2001 to 2500 & $5(17 \%)$ \\
\hline 2501 to 3000 & $3(10 \%)$ \\
\hline$>3500$ & $2(6.7 \%)$ \\
\hline \multicolumn{2}{|c|}{ RARPs performed in center/network yearly } \\
\hline$<500$ & $20(67 \%)$ \\
\hline 501 to 1000 & $5(17 \%)$ \\
\hline 1001 to 1500 & $1(3.3 \%)$ \\
\hline 1501 to 2000 & $2(6.7 \%)$ \\
\hline 2501 to 3000 & $1(3.3 \%)$ \\
\hline$>3500$ & $1(3.3 \%)$ \\
\hline
\end{tabular}


Urologists performing RARP in your center/network

1 to 3

$9(30 \%)$

4 to 6

$17(57 \%)$

7 to 9

$3(10 \%)$

10 to 12

$1(3.3 \%)$

Country of origin

Belgium

$4(13 \%)$

Great Britain

$4(13 \%)$

Italy

$4(13 \%)$

Germany

$3(10 \%)$

France

$3(10 \%)$

The Netherlands

$3(10 \%)$

Australia

$1(3.3 \%)$

Greece

$1(3.3 \%)$

India

$1(3.3 \%)$

Spain

$1(3.3 \%)$

Turkey

$1(3.3 \%)$

Czech Republic

1 (3.3\%)

United States

$1(3.3 \%)$

Sweden

$1(3.3 \%)$

Switzerland

$1(3.3 \%)$

*Seven respondents had multiple occupations.

*Three respondents were professor, chief and trainer. Two respondents were professor and chief. One respondent was professor and trainer. One respondent was chief and trainer.

The use of postoperative results analysis and surgical video review in daily practice All respondents record surgical videos of their cases. Twenty-seven of the $30(90 \%)$ respondents organized periodical postoperative result analysis meetings, of whom $17(56 \%)$ included surgical video review (Table 2). One respondent was in the process of including surgical video review in their clinic. The postoperative results analyses were held at various intervals. Two respondents analyzed and reviewed 
the data alone. Twenty-five (83\%) respondents held the meetings in a team, of which eight only with urology staff, 13 with urology staff and residents, and four held one-on-one meetings. None invited nurses or operating room staff to the review meeting.

Table 2: Organization of postoperative result analysis

\begin{tabular}{|l|l|}
\hline Do you organize postoperative result analysis? & \\
\hline Yes & $27(90 \%)$ \\
\hline Interval & $7(26 \%)$ \\
\hline Once a month & $1(3.7 \%)$ \\
\hline Once every two months & $9(30 \%)$ \\
\hline Once every three months & $9(30 \%)$ \\
\hline Twice a year & $3(11 \%)$ \\
\hline Once a year & \\
\hline Setting & $2(7.4 \%)$ \\
\hline Alone & $8(30 \%)$ \\
\hline Group meeting, staff only & $13(48 \%)$ \\
\hline Group meeting including residents & $4(15 \%)$ \\
\hline One on one & \\
\hline Do you include video reviews? & $7(41 \%)$ \\
\hline Always & $7(41 \%)$ \\
\hline $75 \%$ of the time & $2(12 \%)$ \\
\hline $50 \%$ of the time & $1(5.9 \%)$ \\
\hline $25 \%$ of the time & \\
\hline In what way are videos shown? & $11(65 \%)$ \\
\hline Edited videos, only certain phases & $6(35 \%)$ \\
\hline Fast forwarded video's & \\
\hline Are videos shown of one surgeon or multiple surgeons & $3(18 \%)$ \\
\hline One surgeon & $14(82 \%)$ \\
\hline Multiple surgeons & $1(5.9 \%)$ \\
\hline Provision of background information during video reviews & $1(5.9 \%)$ \\
\hline Blind & $4(24 \%)$ \\
\hline Yes case information after preliminary discussion & $11(65 \%)$ \\
\hline Yes, case information only & \\
\hline Yes, case information and surgeon information & $4(24 \%)$ \\
\hline Provision of feedback based on video review & $11(65 \%)$ \\
\hline Yes, at a later time one-on-one verbally & $2(12 \%)$ \\
\hline Yes, during the meeting & \\
\hline No & \\
\hline
\end{tabular}

Different strategies of postoperative results analysis and surgical video review

All of the respondents who incorporated video review showed either fast-forwarded or edited videos (i.e. specific phases of the surgery of fast-forwarded videos). Respondents reported several limitations of video review: lack of storage capacity, lack of structured video database, no structured analysis of videos, lack of time to edit and view videos, and privacy issues. Three respondents reported no limitations and one respondent stated they have staff editing the video material and have extra servers to store video cases. Other respondents would tackle stated limitations by clearing time schedule of staff and residents to view videos, hiring staff to edit videos to only see the relevant frames, creating a structured database with easy storage and acces to videos that meets privacy standards. 
All but one respondents (96\%) recommended implementation of video review, even those who did not yet practice it. They assumed it improves outcomes through self-reflection, feedback from a colleague who might see details they did not, or from observing different techniques and 'tricks' of a colleague. The participants stated it is important for both residents and staff to take a step back and view their own and others' techniques. It made them realize their limitations and where to focus their improvement. The respondents believe video reviewing improves skills such as dexterity, speed, tissue handling. One respondent who incorporated video reviewing in the training program of residents stated "Changes [in skills] happen in real time. I see the benefits of their efforts with each succeeding case." The respondents advised similar formats: choose videos of complications or specific surgical steps, periodically review and discuss these videos in a panel of experts/colleagues or with mentor and residents, be open-minded to feedback and apply the feedback to improve daily clinical practice. Some participants suggested virtual messenger based groups to share short, deidentified videos with other experts or to send a video to an expert for reviewing. Future recommendations to improve the video review process were: standardized measurements (definition of failure), standardized reporting system, relating errors and complications to functional outcomes, relating specific surgical steps to outcomes.

The use of postoperative results analysis and surgical video review in improving daily practice and reduction of complications.

All respondents intended to adapt daily practice based on their periodical postoperative results analysis. Two respondents required their urologists and urologists in training to perform RARP under guidance through a dual console Da Vinci robot, either at random or when they do not meet self-constructed quality criteria. Eight respondent (26\%) specifically stated they adapted the surgical approach and postoperative care based on postoperative result analysis, video review and team discussions. They adapted surgical techniques in specific steps of the surgery, rejected techniques of limited benefit and analyzed the results after a set number of months to create a continuous feedback loop. This has also led to changes in patient selection, due to the fact that some techniques are less suitable for specific cases.

During the meetings, topics of interest were challenging cases (such as patients with high BMI, large prostate volumes), margin status, functional outcomes and surgical complications based on Clavien Dindo classification. When assessing functional outcomes, most respondents reviewed those cases with optimal and bad outcomes and compared the surgical techniques on the videos. The reviewed cases had various subjects: outlined surgical complications, salvage treatments, unusual/important findings or specific phases of surgery.

Factors of interest in postoperative results analysis and surgical video review related to improvement of postoperative functional outcomes and reduction complications

Seventeen participants answered the following questions (Table 3). When asked what steps of the RARP possibly influence postoperative continence, 16 (94\%) respondents answered 'management of prostate apex/urethra' and 'urethro-vesical anastomosis.' Fourteen (82\%) respondents assumed 'nerve preservation' to influence recovery of continence. Twelve (71\%) thought that 'bladder neck dissection' and $15(88 \%)$ thought that 'urethro-vesical anastomosis' influences continence. All respondents believed 'neurovascular bundles preservation' and 14 (82\%) believed that 'management of prostate apex/urethra' influences postoperative erectile function. Four (24\%) respondents regard 'bladder neck dissection' and 11 
(65\%) regarded 'ligation of prostate pedicles' as important steps in preservation of erectile function. Factors regarded as being positively or negatively associated with complications and outcomes are represented in Table 4.

Table 3: Respondents' perception of the influence of surgical steps on outcomes

Total respondents answering the following questions

Which of the surgical steps are of interest to you when looking at continence?

(multiple answers possible)

Abdominal cavity approach/port placement

Retropubic space approach/mobilisation of Retzius

Pelvic floor muscle exposure/opening of the endopelvic fascia

Bladder neck dissection

Ligation of prostate pedicles

Nerve preservation

Management of prostate apex/urethra

Prostate removal

Urethro-vesical anastomosis

Lymph node dissection

17

Which of the surgical steps are of interest to you when looking at erectile function? (multiple answers possible)

Pelvic floor muscle exposure/opening of the endopelvic fascia

Bladder neck dissection

Ligation of prostate pedicles

Nerve preservation

Management of prostate apex/urethra

Urethro-vesical anastomosis

Lymph node dissection

Retropubic space approach/mobilisation of Retzius

$1(5.9 \%)$

$4(24 \%)$

$10(59 \%)$

$12(71 \%)$

$4(4 \%)$

$14(82 \%)$

$16(94 \%)$

$2(12 \%)$

$15(88 \%)$

$3(18 \%)$
$9(53 \%)$

$4(24 \%)$

$11(65 \%)$

$17(100 \%)$

$14(82 \%)$

$5(29 \%)$

$4(24 \%)$

$1(5.9 \%)$

Table 4: Factors associated with complications and outcomes

\begin{tabular}{|l|l|}
\hline Beneficial & Detrimental \\
\hline Lower age & Higher age \\
\hline Narrow bladder neck & Overweight \\
\hline Moment of surgery & Comorbidity \\
\hline Patient positioning & Prior abdominal surgery \\
\hline Surgical technique & $\begin{array}{l}\text { Previous transurethral resection of the prostate or Salvage } \\
\text { prostatectomy }\end{array}$ \\
\hline Surgeon experience & Pelvic radiation \\
\hline $\begin{array}{l}\text { Peri-operative checks e.g. bladder } \\
\text { filling to check for leakage }\end{array}$ & Surgical errors \\
\hline $\begin{array}{l}\text { Peri-operative anesthesiologic } \\
\text { planning }\end{array}$ & Pelvic lymph node dissection \\
\hline $\begin{array}{l}\text { Expertise of and communication } \\
\text { with bedside assistance }\end{array}$ & Extensive blood loss \\
\hline Postoperative care & $\begin{array}{l}\text { Coagulation during 'management of prostate apex/urethra', 'urethro- } \\
\text { vesical anastomosis' and 'nerve preservation }\end{array}$ \\
\hline
\end{tabular}

\section{Discussion}

A survey was performed amongst international RARP surgeons to gain insight into the use, extent and possible effect of postoperative results analysis and surgical video review in daily clinical practice.

The use of postoperative results analysis and surgical video review in daily practice 
Results of this study show both postoperative results analysis and surgical video review are used in the daily practice of most experts surveyed. Most of the respondents select cases for video review based on the postoperative results. Those respondents who have not yet implemented surgical video review are interested in implementation of video review in their practice. Three respondents did not use postoperative results analysis or surgical video review in their practice.

Different strategies of postoperative results analysis and surgical video review Although the frequency and structure of these meetings vary, results of this study show RARP surgeons assume video analysis benefits postoperative results. Most RARP surgeons do not use entire videos but only use phases of videos during the video review. They edit the video to only show phases that the RARP surgeons feel are of interest concerning the outcome of the specific case. During the review meetings in the clinics of the surgeons included in this study, most teams show videos of different urologists of their center whilst discussing data of the patient and surgeon. In one clinic, case information is presented without identifying the surgeon. In most clinics, feedback on the surgical techniques observed in the videos is given during these meetings.

The use of postoperative results analysis and surgical video review in improving daily practice and reduction of complications.

All surgeons included in this study think surgical video review should be implemented not only for trainees but also as a form of self-reflection for established surgeons. This is in agreement with the results of our previous publication. ${ }^{1}$ RARP surgeons feel the implementation of postoperative results analysis and surgical video review could reduce complications and improve outcomes, this is similar to the results of the study by Schlomm et al. ${ }^{8}$ and Cathcart et al. ${ }^{9}$.

Multiple RARP surgeons use the postoperative results analysis and surgical video review as a manner to evaluate their surgical results and check the effects of changes in surgical approach. Two respondents use a dual console of the robot to perform live reviews of random surgeries as a form of quality assurance.

Factors of interest in postoperative results analysis and surgical video review related to improvement of postoperative functional outcomes and reduction complications

Results of the current study may be compared to the results of an earlier Delphi study performed by our group. ${ }^{1}$ The results of the current study are in contrast to our earlier study in which 'management of prostate apex/urethra' and 'nerve preservation' are not mentioned as a factor influencing postoperative urinary continence. ${ }^{1}$ In both studies agreement was reached on the role perceived quality of the 'urethrovesical anastomosis' concerning postoperative recovery of urinary continence. ${ }^{1}$ Goldenberg et al. evaluated the influence of surgical skills on functional outcomes using GEARS ${ }^{15}$, an assessment tool scoring surgical performance with a 5-point Likert scale in six domains (perception, dexterity, efficiency, force sensitivity, autonomy, robotic control). They found significantly higher GEARS scores for the steps 'bladder neck dissection' and 'urethro-vesical anastomosis' in continent vs. incontinent patients². 
Factors indicated to influence complications and outcomes by the surgeons in this study match the results of our earlier Delphi study in a group of Dutch experts. ${ }^{1}$ This study adds insight into how video review can be used to learn how to influence these factors in order to improve outcome. Earlier research by Birkmeyer et al. has shown it is possible to use surgical videos to predict complications and postoperative outcome. ${ }^{6}$

A possible influence to the use of postoperative results analysis and surgical video review in daily practice not raised by the RARP surgeons could be the new and more stringent General Data Protection Regulation (GDPR) in the European Union. ${ }^{16}$ Systems should be put in place to assure safe data storage and privacy protection of the patient. Further investigation into the influence of the new GDRP on the use of postoperative results analysis and surgical video review should be performed. One solution is the anonymization of both surgical video and patient data but this makes correlation of additional follow-up information to the peri-operative data and the surgical video impossible.

\section{Limitations}

The relatively low overall response rate (32\%) may reflect the interest in this topic in the urological field. Whereas the responders were generally positive towards data review, the majority of surveyed centers did not respond. If this observation reflects reduced time availability for data review this is reason for concern given the positive effects of structured data review. The results of this study give the first insights into the experienced value of postoperative results analysis and surgical video review in the daily practice of RARP surgeons worldwide and a significant number of urologists were invited for the survey. Although the experts originated from 15 different countries, the majority of surgeons who completed the questionnaire came from western European country's. Although it is possible that we missed urologists who use postoperative results analysis and surgical video review, we expect that, since the responses of these participants were homogenous, the results in this study represent a near complete overview on the topic. Potentially, 63 more respondents could have given their insight into video review analysis. Two respondents did not fully answer the video review questions.

\section{Suggestions for future research}

Although there is some discrepancy between the results of this study and the results of our previous Delphi survey amongst Dutch experts ${ }^{1}$, the results of the present study give additional insights into the acceptance of postoperative results analysis and surgical video review amongst European experts in RARP. The level of detail in the surgical and anatomical factors indicated by the experts gives more insight into which specific factors experts assume to be associated with surgical complications and negative functional outcomes. This information can give rise to additional fields of research such as the training of artificial intelligence to recognize surgical errors and events in order to help in the selection of surgical videos for review. Additionally, factors identified by the experts could be used to train human observers or Machine learning algorithms to observe and analyze the surgical videos, and to evaluate whether the relation between postoperative outcomes and the factors identified by the experts could be objectified. 


\section{Conclusion}

The majority of interviewed RARP surgeons have adopted the implementation of postoperative results analysis and surgical video review in their daily practice as a form of quality assurance and as a form of self-reflection. Since only a minority of surgeons responded to the survey this raises concern on the application of data review in daily practice in non-responders. Most of the responding surgeons use edited surgical videos during team meetings to discuss RARP cases and gain insights into surgical handling and postoperative results. The information provided in this survey gives information on the best method of implementation of video review and gives rise to additional fields of research on the origins of surgical complications and adverse postoperative functional results.

\section{Abbreviations}

CC-ERUS: Certified Curriculum of European Association of Urology Robotic Urology Section

EAU: European Association of Urology

RAS: Robot Assisted Surgery

RARP: Robot-Assisted Radical Prostatectomy

\section{Declarations}

\section{Ethics approval and consent to participate}

At te start of the questionnaire the participants were informed that all data would be analysed anonymously. Informed consent was given by all participants. Under Dutch law no ethical review is necessary for this type of study.

\section{Consent for publication}

Not applicable

\section{Availability of data and materials}

The datasets used and analysed during the current study are available from the corresponding author on reasonable request.

\section{Competing interests}

The authors declare that they have no competing interests

\section{Funding}

This work was supported by Astellas Pharma Europe Ltd. and Olympus B.V. 


\section{Authors' contributions}

1. J.W. Beulens and H. Veerman had full access to all the data in the study and takes responsibility for the integrity of the data and the accuracy of the data analysis.

Study concept and design: van der Poel, Brinkman, Veerman, Beulens

Acquisition of data: Veerman, Beulens, van der Poel

Analysis and interpretation of data: van der Poel, Brinkman, Beulens, Veerman

Critical revision of the manuscript for important intellectual content: Bangma, Wagner, van der Poel, Veerman, van Basten, Hendrikx, Koldewijn, van Merriënboer, Brinkman, Beulens

Statistical analysis: Beulens, Veerman

Obtaining funding: None.

Administrative, technical, or material support: Beulens

Supervision: Bangma, Wagner, van der Poel.

Other: None.

\section{Acknowledgements}

The authors acknowledge the Quality and Safety of Robot-Assisted Surgery Working_group: for their contibution in this work: Sjoerd Klaver, Alex Mottrie, Christian Wagner, F. Montorsi, E. Canda, J.P. Redorta, H Beerlage, R. Sanchez-Salas, T. Ahlering, G. Ahlgren, W. Artibani, E. Barret, D. Murphy, C. Vaessen, B. Van Cleynenbreugel, J. Witt, Paolo Dell Oglio, N. Fossati, N. Grivas, M. Agostino, S. Nathan, M. Naudin, N. Raison, J. Schram, Paolo Umari, P. Uvin, G. Shaw, A. Kumar, and A. Haese

\section{References}

1. Beulens AJW, Brinkman WM, Van der Poel HG, Vis AN, van Basten JP, Meijer RP, Wijburg CJ, Hendrikx AJM, van Merriënboer JJG, Wagner C. Linking surgical skills to postoperative outcomes: a Delphi study on the robot-assisted radical prostatectomy. J Robot Surg [Internet]. 2019;

2. Goldenberg MG, Goldenberg L, Grantcharov TP. Surgeon Performance Predicts Early Continence After Robot-Assisted Radical Prostatectomy. J Endourol [Internet]. 2017 Jun 26 [cited 2018 Jun 18];31(9):end.2017.0284.

3. Hung AJ, Chen J, Che Z, Nilanon T, Jarc A, Titus M, Oh PJ, Gill IS, Liu Y. Utilizing Machine Learning and Automated Performance Metrics to Evaluate Robot-Assisted Radical Prostatectomy Performance and Predict Outcomes. J Endourol [Internet]. 2018 May [cited 2019 Jul 25];32(5):43844. 
4. Varban OA, Niemann A, Stricklen A, Ross R, Ghaferi AA, Finks JF, Dimick JB. Far from Standardized: Using Surgical Videos to Identify Variation in Technique for Laparoscopic Sleeve Gastrectomy. J Laparoendosc Adv Surg Tech [Internet]. 2017 Aug 1 [cited 2017 Aug 18];27(8):761-7.

5. Oussi N, Loukas C, Kjellin A, Lahanas V, Georgiou K, Henningsohn L, Felländer-Tsai L, Georgiou E, Enochsson L. Video analysis in basic skills training: a way to expand the value and use of BlackBox training? Surg Endosc [Internet]. 2017 Jun 29 [cited 2017 Aug 18];1-9.

6. Birkmeyer JD, Finks JF, O 'reilly A, Oerline M, Carlin AM, Nunn AR, Dimick J, Banerjee M, Birkmeyer NJO. Surgical Skill and Complication Rates after Bariatric Surgery for the Michigan Bariatric Surgery Collaborative. N Engl J Med [Internet]. 2013 [cited 2017 Nov 17];369:1434-42.

7. Goldenberg MG, Lee JY, Kwong JCC, Grantcharov TP, Costello A. Implementing assessments of robot-assisted technical skill in urological education: a systematic review and synthesis of the validity evidence. Vol. 122, BJU International. 2018.

8. Schlomm T, Huland H, Graefen M. Improving outcome of surgical procedures is not possible without adequate quality measurement. Eur Urol [Internet]. 2014;65(6):1017-9.

9. Cathcart P, Sridhara A, Ramachandran N, Briggs T, Nathan S, Kelly J. Achieving quality assurance of prostate cancer surgery during reorganisation of cancer services. Eur Urol [Internet]. 2015 Jul 1 [cited 2018 Apr 5];68(1):22-9.

10. Brinkman W, de Angst I, Schreuder H, Schout B, Draaisma W, Verweij L, Hendrikx A, van der Poel H. Current training on the basics of robotic surgery in the Netherlands: Time for a multidisciplinary approach? Surg Endosc Other Interv Tech. 2017;31(1):281-7.

11. Beulens AJW, Brinkman W, Porte P, Meijer R, Van Merriënboer J, Van Der Poel H, Wagner C. The value of a one-day multidisciplinary robot surgery training for novice robot surgeons. J Robot Surg. 2018;

12. Hussein AA, Ghani KR, Peabody J, Sarle R, Abaza R, Eun D, Hu J, Fumo M, Lane B, Montgomery JS, Hinata N, Rooney D, Comstock B, Chan HK, Mane SS, Mohler JL, Wilding G, Miller D, Guru KA. Development and Validation of an Objective Scoring Tool for Robot-Assisted Radical Prostatectomy: Prostatectomy Assessment and Competency Evaluation. J Urol [Internet]. 2017 [cited 2017 Jun 12];197(5):1237-44.

13. van Basten JPA, Somford RM, de Baaij J, Sedelaar M, Vrijhof E. Initiatief Comprehensive Prostate Cancer Network (CPCN) in Zuidoost Nederland. Tijdschr voor Urol. 2017;7(6-7):134-44.

14. Kong H, West S. WMA DECLARATION OF HELSINKI - ETHICAL PRINCIPLES FOR Scienti C Requirements and Research Protocols. W [Internet]. 2013;(June 1964):29-32.

15. Goh AC, Goldfarb DW, Sander JC, Miles BJ, Dunkin BJ. Global evaluative assessment of robotic skills: Validation of a clinical assessment tool to measure robotic surgical skills. J Urol [Internet]. 2012 Jan 1 [cited 2017 Aug 29];187(1):247-52.

16. European Parliament and of the Council. Regulation (EU) 2016/679 of 27 April 2016 on the protection of natural persons with regard to the processing of personal data and on the free movement of such data, and repealing Directive 95/46/EC (General Data Protection Regulation). Off J Eur Communities [Internet]. 2016;OJ L 119/1:1-88. 
Figures

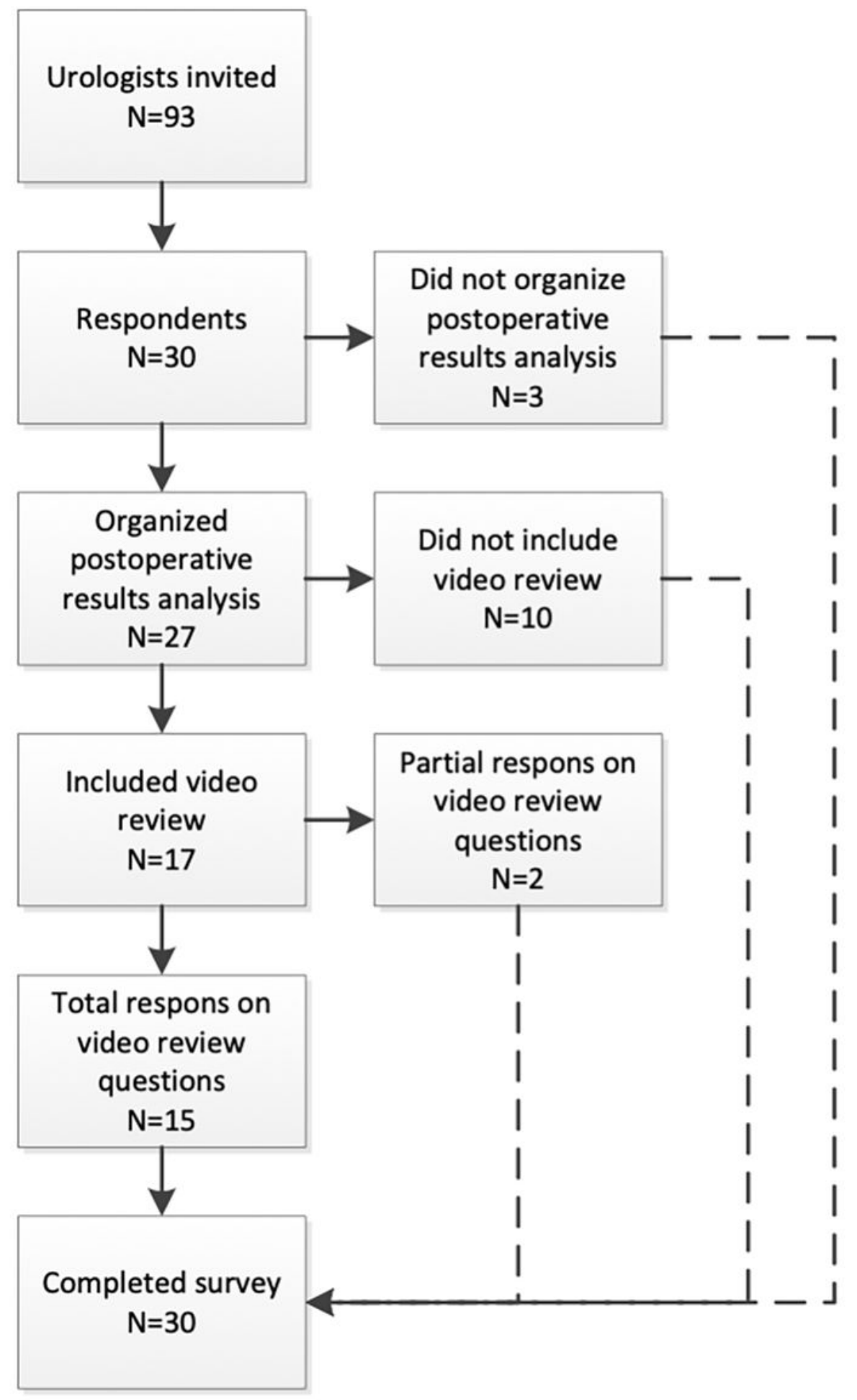

Figure 1

Flow diagram of response. 